\title{
Phytochemical Evaluation of Extracts and GC-MS analysis of oil from Monodora myristica Seed
}

\author{
Wilfred 0. Obonga, Edwin 0. Omeje, Charles 0. Nnadi \\ and Wilson G. Ocheme
}

\author{
Department of Pharmaceutical and Medicinal Chemistry, Faculty of Pharmaceutical Sciences, University of \\ Nigeria, 410001 Nsukka, Enugu State, Nigeria
}

(Received: October 12, 208; Accepted: January 01, 2019; Published (Web): June 30, 2019)

\begin{abstract}
Monodora myristica is one of the plants used extensively in folkloric medicine across West Africa. Despite the ethnopharmacological relevance of the plant, the phytochemical details, especially of the oil-rich seed, have not been completely elucidated. This study was designed to ascertain the phytochemical constituents of extracts of $M$. myristica seed oil and characterize the oil constituent using gas chromatography-mass spectrometry. The phytochemical screening was done using standard methods and the oil was characterized by GC-MS analysis. The result of the phytochemical screening showed the presence of terpenoids, sterols, saponins, tannins, flavonoids and cardiac glycoside in variable quantities. The GC-MS analysis revealed huge presence of fatty acids, terpenoids and other related compounds. The major compounds found in the oil of the seeds were $o$-cymene (2), $\gamma$-terpinene (3), nopinane (4), limonene (5), carvotanacetone (6), $\beta$-pinene (7), aromadendrene (9), germacrene (11), $\alpha$-amorphene (13) and copaene (14). The rich phytoconstituents present in the seed oil could be the basis of its acclaimed ethnomedicinal uses across West Africa and beyond.
\end{abstract}

Key words: Monodora myristica, phytochemical, oil, GC-MS

\section{INTRODUCTION}

Monodora myristica is a tropical tree of the Annonacea family of flowering plants widely distributed in sub-Saharan Africa, ${ }^{1,2}$ and some parts of Central and South America. ${ }^{3,4}$ In Nigeria, the plant is variously referred as Iwor (Itsekiri), Gujiya dan miya (Hausa), Ikposa (Benin), Ehuru (Igbo) and arigbo or eyi naghose (Yoruba), Ehinawosin (Ikale), Uyengben (Edo) and Fausse noix de muscade (French). ${ }^{5}$ M. myristica has both economic and medicinal benefits. ${ }^{6}$ Its stimulant, antiemetic, aperient, stomachic and tonic properties of the seed are well known ${ }^{7}$ and the high mineral and essential oil constituents also provide nutritional benefits. ${ }^{8}$ The seeds are rich in flavonoids, terpene, resins, anthraquinones, tannins, cyanogenic glycosides, alkaloids, arocine, lactose, saponins and steroids. ${ }^{8}$ Some fifty-three phenolic

Correspondence to: Wilfred O. Obonga

Phone: +234-803-330-5022;

E-mail: wilfred.obonga @unn.edu.ng

Dhaka Univ. J. Pharm. Sci. 18(1): 69-73, 2019 (June) DOI: https://doi.org/10.3329/dujps.v18i1.41893 compounds from the chloroform extract in addition to a few oils from the apolar solvent extract such as myrcene, $\alpha$-pinene, limonene and $\alpha$-phellandrene have been characterized. ${ }^{9,10}$ More so, several of the activities of the $M$. myristica seed have been attributed to these phytochemicals. ${ }^{11-13}$ Although previous works have reported several biological activities of these extracts, information on the exact phytochemical(s), especially the oily-rich constituents, responsible for the bioactivities have obviously not been exhaustively described. For instance, only about ten phytochemicals were characterized by Adewole and co-workers, ${ }^{10}$ this might represent a few percentage of the bulk constituents considering the high levels of myristicin (42.60\%), caffeic acid (23.39\%), elemicin $(3.82 \%)$ and eugenol $(1.02 \%)^{14}$ and $5.9 \%$ colourless essential oil $^{12}$ contents previously reported. The present work, therefore, aimed to evaluate the crude extracts and solvent fractions with a view of understanding the distribution of the phytoconstituents across solvents 
of different polarities. In addition, the GC-MS fingerprint of the seed oil is characterized to further expand the library of phytochemicals identified from M. myristica seed.

\section{MATERIALS AND METHODS}

Chemicals. All chemicals used for the study were of analytical grade and are described in the relevant sections. Unless otherwise stated, the chemicals and reagents were of appropriate grades from Sigma-Aldrich, Darmstadt, Germany and were used as supplied.

Seed collection. The seeds were purchased in April 2015 from a local market in Nsukka Nigeria. The sample was initially identified by a botanist, Mr. John Ahiaba from Kogi State University Anyigba and authenticated by a taxonomist, Mr. Alfred Ozioko, of the International Centre for Ethnomedicine and Drug Development (InterCEED) Nsukka, Nigeria. The sample was deposited in the InterCEED herbarium with the identification number, InterCEED 3045-12.

Extraction of $\boldsymbol{M}$. myristica seed oil. Exactly 900 g quantity of the powdered M. myristica seed (in portions of $9 \times 100 \mathrm{~g}$ ) was weighed and extracted exhaustively for $12 \mathrm{hrs}$ in a Soxhlet extraction apparatus, with heater (Merck Chemicals $\mathrm{GmbH}$, Darmstadt, Germany) using $4.5 \mathrm{~L}$ petroleum ether at the regulated temperature of $40-60^{\circ} \mathrm{C}$. The solvent of the combined extracts was evaporated in vacuo at $40^{\circ} \mathrm{C}$ using rotary vacuum evaporator (Rotavapor R210, BÜCHI, Flawil, Switzerland) to a dry weight of $22.7 \%$. The oil was stored at $4^{\circ} \mathrm{C}$ prior to use and the defatted mass was preserved for further solvent extraction.

Extraction of $M$. myristica seed. Further extraction of the dried mass was carried out by cold maceration. A quantity of exactly $600 \mathrm{~g}$ of the defatted mass of $M$. myristica seed was weighed and macerated into $1.5 \mathrm{~L}$ of $95 \% \mathrm{v} / \mathrm{v}$ methanol for a period of $24 \mathrm{hrs}$. The extraction was performed with four successive portions of fresh solvents and the combined extracts were completely evaporated invacuo with a rotary vacuum evaporator at $40^{\circ} \mathrm{C}$ to dry weight of $7.4 \%$. The obtained extract was evaluated for phytochemical studies.

Fractionation of the extract from the mass of M. myristica. The obtained extract (44 g) was dissolved in $10 \% \mathrm{v} / \mathrm{v}$ aqueous methanol and partitioned successively in equal volumes of the following solvents in the order of $n$-hexane, dichloromethane, ethyl acetate and $n$-butanol. The respective solvent fractions of the extract were concentrated to dryness in vacuo at $40^{\circ} \mathrm{C}$ and stored appropriately.

Phytochemical investigation. The crude methanol extract, solvent fractions and the extracted oils were tested for the phytochemical constituents such as flavonoids, tannins, cardiac glycosides, triterpenoids, steroids and saponins. These evaluations were done according to the methods described by Sofowora et al. and the methods of Trease and Evans. ${ }^{15}$

Gas Chromatography-Mass Spectrophotometric analysis. The constituents of the crude oily extract were analyzed using GC-MS QP2010 coupled with MS-5973-634071 Series under these specified conditions; Column oven temperature of $70.0^{\circ} \mathrm{C}$ (increasing to $280^{\circ} \mathrm{C}$ in $5 \mathrm{~min}$ at flow rate of 10 $\mathrm{ml} / \mathrm{min}$ ). Injection temperature of $250.0^{\circ} \mathrm{C}$ with split flow injection and linear velocity flow control modes. The velocity pressure was maintained at $116.9 \mathrm{kPa}$ with total flow rate of $40.8 \mathrm{ml} / \mathrm{min}$, column flow rate of $1.80 \mathrm{ml} / \mathrm{min}$ and linear velocity of $49.2 \mathrm{~cm} / \mathrm{sec}$. The purge flow rate of $3.0 \mathrm{ml} / \mathrm{min}$ and split ratio of 20.0 were used. The ion source temperature was $200.0^{\circ} \mathrm{C}$, interface temperature of $250.0^{\circ} \mathrm{C}$, solvent cut time of $2.5 \mathrm{~min}$. The MS start time was $3.0 \mathrm{~min}$; end time was $24.0 \mathrm{~min}$, scan event time of $0.5 \mathrm{sec}$, scan speed of 666 . The start $\mathrm{m} / \mathrm{z}$ of 30.00 and end $\mathrm{m} / \mathrm{z}$ of 350.00 .

\section{RESULTS}

Phytochemical constituents of the oil, extract from mass and the fractions from $M$. myristica seed. The result in Table 1 shows the relative phytochemical composition of the oil, extract from mass and fractions from M. myristica seed. The oily 
extract was rich in sterols and triterpenoids. The triterpenoid composition of the oil was in same proportion with $n$-hexane and dichloromethane extracts. Similarly, sterols and triterpenoids in crude marc extract and ethyl acetate fractions were moderate. Expectedly, there was trace amount of cardiac glycosides, flavonoids, tannin and saponin in the oily crude extract and $n$-hexane solvent fraction of the marc extract.

Result of GC-MS analysis. By the critical evaluation and spectrum comparison of the GC-MS spectra of the oil extract, the following compounds in Table 2 were unambiguously identified.

Table 1. Relative phytochemical composition of $M$. myristica seed.

\begin{tabular}{|c|c|c|c|c|c|c|}
\hline Sample tested & Sterols & Triterpenoids & Glycoside & Flavonoids & Tannin & Saponin \\
\hline Oily crude extract & +++ & +++ & - & - & - & - \\
\hline Marc crude extract & ++ & ++ & ++ & + & + & ++ \\
\hline$n$-Hexane & ++ & +++ & - & - & - & - \\
\hline Dichloromethane & ++ & +++ & - & + & - & - \\
\hline Ethyl acetate & ++ & ++ & + & + & ++ & + \\
\hline$n$-Butanol & + & ++ & + & ++ & + & + \\
\hline Aqueous & + & ++ & + & + & - & + \\
\hline
\end{tabular}

$(-)=$ absent,$(+)=$ present in small quantity, $(++)=$ moderately present, $(+++)=$ present in large quantity

Table 2. GC-MS constituents of M. myristica seed oil.

\begin{tabular}{|c|c|c|c|}
\hline Compounds & Formula & MW & CAS \\
\hline 1 & $\mathrm{C}_{10} \mathrm{H}_{16}$ & 136 & $99805-90-0$ \\
\hline 2 & $\mathrm{C}_{10} \mathrm{H}_{14}$ & 134 & $527-84-4$ \\
\hline 3 & $\mathrm{C}_{10} \mathrm{H}_{16}$ & 136 & $99-85-4$ \\
\hline 4 & $\mathrm{C}_{10} \mathrm{H}_{16}$ & 136 & $16022-04-1$ \\
\hline 5 & $\mathrm{C}_{10} \mathrm{H}_{16}$ & 136 & $138-86-3$ \\
\hline 6 & $\mathrm{C}_{10} \mathrm{H}_{16} \mathrm{O}$ & 152 & $499-71-8$ \\
\hline 7 & $\mathrm{C}_{10} \mathrm{H}_{16}$ & 136 & $127-91-2$ \\
\hline 8 & $\mathrm{C}_{11} \mathrm{H}_{16} \mathrm{O}$ & 164 & $0-00-0$ \\
\hline 9 & $\mathrm{C}_{15} \mathrm{H}_{24}$ & 204 & $109119-91-7$ \\
\hline 10 & $\mathrm{C}_{15} \mathrm{H}_{24}$ & 204 & $489-40-7$ \\
\hline 11 & $\mathrm{C}_{15} \mathrm{H}_{24}$ & 204 & $23986-74-5$ \\
\hline 12 & $\mathrm{C}_{15} \mathrm{H}_{24}$ & 204 & $17334-55-3$ \\
\hline 13 & $\mathrm{C}_{15} \mathrm{H}_{24}$ & 204 & $483-75-0$ \\
\hline 14 & $\mathrm{C}_{15} \mathrm{H}_{24}$ & 204 & $3856-25-5$ \\
\hline 15 & $\mathrm{C}_{15} \mathrm{H}_{24}$ & 204 & $118-65-0$ \\
\hline 16 & $\mathrm{C}_{17} \mathrm{H}_{34} \mathrm{O}_{2}$ & 270 & $5129-60-2$ \\
\hline 17 & $\mathrm{C}_{18} \mathrm{H}_{36} \mathrm{O}_{2}$ & 284 & $57-11-4$ \\
\hline 18 & $\mathrm{C}_{19} \mathrm{H}_{34} \mathrm{O}_{2}$ & 294 & $2566-97-4$ \\
\hline 19 & $\mathrm{C}_{19} \mathrm{H}_{38} \mathrm{O}_{2}$ & 298 & $112-61-8$ \\
\hline 20 & $\mathrm{C}_{18} \mathrm{H}_{34} \mathrm{O}_{2}$ & 282 & $112-80-1$ \\
\hline 21 & $\mathrm{C}_{19} \mathrm{H}_{34} \mathrm{O}_{2}$ & 294 & $56630-73-0$ \\
\hline 22 & $\mathrm{C}_{21} \mathrm{H}_{42} \mathrm{O}_{2}$ & 326 & $1120-28-1$ \\
\hline 23 & $\mathrm{C}_{19} \mathrm{H}_{38} \mathrm{O}$ & 282 & $0-00-0$ \\
\hline 24 & $\mathrm{C}_{22} \mathrm{H}_{44} \mathrm{O}_{2}$ & 340 & $6064-90-0$ \\
\hline 25 & $\mathrm{C}_{23} \mathrm{H}_{46} \mathrm{O}_{2}$ & 354 & $929-77-1$ \\
\hline
\end{tabular}


4-Methyl-3-(1'-methylethylidene)-1-cyclohexene (1), 1-Methyl-2-(1'-methylethyl)benzene (2), 1-Methyl-4(1'-methylethyl)-1,4-Cyclohexadiene (3), 6,6Dimethyl-3-methylenebicyclo[3,1,1]heptanes (4), 1Methyl-4-(1'-methylethenyl)-1-cyclohexene (5), 2Methyl-5-(1'-methylethyl)-2-cyclohexene-1-one (6), 6,6-Dimethyl-2-methylenebicyclo[3,1,1]heptanes (7), 4(2'-Methylcyclohex-1'-enyl)-but-2-enal (8), 1,1,7Trimethyl-4-methylenedecahydro-1H-cyclopropa-

[e]azulene (9), 1a,2,3,4a,5,6,7b-Octahydro-1,1,4,7tetramethyl-1H-Cycloprop[e]azulene (10), 1-Methyl5-methylene-8-(1'-methylethyl)-1,6-Cyclodecadiene

(11), 1a,2,3,5,6,7,7a,7b-Octahydro-1,1,7,7-tetramethyl-1H-cyclopropa[a]naphthalene (12), 1,2,4a,5, 6,8a-Hexahydro-4,7-dimethyl-1-(1'-methylethyl) naphthalene (13), 1,3-Dimethyl-8-(1'-methylethyl) tricyclo[4,4,0 $\left.0^{0,2,7}\right]$ dec-3-ene (14), 4,11,11-Trimethyl8-methylenebicyclo[7,2,0] undec-4-ene (15), 14Methylpentadecanoate (16), Octadecanoic acid (17), Methyl-9,12-octadecadienoate (18), n-Methyl octadecanoate (19), Oleic Acid (20), Methyl-9,15octadecanoate (21), Methyl eicosanoate (22), 18Nonadecen-1-ol (23), Methyl heneicosanoate (24), Methyl docosanoate (25).

\section{DISCUSSION}

M. myristica seed is a rich source of pharmaceutical and nutritional oil. Its application in formulation science has been reported and the appreciably high content $(22.7 \%)$ obtained in this study compares well with those reported in the previous similar studies. ${ }^{1,8}$ The phytochemical analysis of the extracted oil revealed the presence of medicinally important sterols and triterpenoids in high quantities. In particular, steroids-containing plant extract are important in the reduction of risk of coronary heart and neurodegenerative diseases in preand post-menopausal women. ${ }^{4}$ The phytochemical constituents of the fractions showed polarity guided distribution of the phytochemicals in the respective solvents. Sterol and triterpenoids were abundant in $n$-hexane fraction; sterol, triterpenoids and trace of flavonoids in dichloromethane; sterol, triterpenoids, flavonoids, and much more polar constituents, cardiac glycosides, tannin and saponin in ethylacetate and sterol, triterpenoids, flavonoids, tannin and saponin predominantly in $n$-butanol fraction compare well with previous findings. ${ }^{16}$ Armed with this information on the phytochemical constituents of defatted $M$. myristica seeds, a prospective research will be to subject these fractions to several biological assays which will enable the eventual isolation and characterization of the constituent(s) responsible for each observed activity. This is currently on-going.

The GC-MS analysis revealed the presence of about twenty (25) chemically related compounds, some of which have never been reported as constituents of $M$. myristica. Some of these compounds identified through the gas chromatography-mass spectrometry are known to have many important biological and formulation functions; $\alpha$-limonene, for instance, is used to promote weight loss, prevent and treat cancer as well treat bronchitis. ${ }^{17}$ In foods, beverages, and chewing gum, limonene is used as a flavoring agent. In addition, in pharmaceuticals, limonene is added to help medicinal ointments and creams penetrate the skin. ${ }^{18}$ Germacrenes are typically produced in a number of plant species for their antimicrobial and insecticidal properties. ${ }^{19}$ Cis oleic acid and oleic acid (in triglyceride form) is included in the normal human diet as a part of animal fats and vegetable oils. Oleic acid as its sodium salt is a major component of soap as an emulsifying agent. It is also used as an emollient. $^{20}$ Small amounts of oleic acid are used as excipient in pharmaceuticals, and it is used as an emulsifying or solubilizing agent in aerosol products. $^{20}$

As earlier reported by Adewole et al. ${ }^{10}$ the GCMS analysis further revealed presence of many other important compounds; $n$-hexadecanoic acid, pentadecanoic acid, $n$-octadecanoic acid, eicosanoic acid, hexeicosanoic acid, docosanoic acid and 9, 15octadecadienoate. The presence of this class of fatty acids further gives credence to the nutritional values of $M$. myristica seeds and possibly its potential ability to modulate the inflammatory pathways. 


\section{CONCLUSION}

The present study has established the distribution of the phytochemicals of M. myristica seed oil and extract in terms of their polarities and thus provides a clue as to the exact constituents responsible for its numerous applications. The GC-MS analysis showed known constituents but were never reported previously as present in M. myristica.

\section{REFERENCES}

1. Burubai, W., Amula, E., Daworiye, P., Suowari T. and Nimame, P. 2009. Proximate composition and some technological properties of African nutmeg (Monodora myristica ) seeds. Electron. J. Environ. Agric. Food Chem. 8, 396-402.

2. Ojiako, O.A., Igwe, C.U., Agha, N.C., Ogbuji. C.A. and Onwuliri, V.A. 2010. Protein and amino acid compositions of Sphenostylis stenocarpa, Sesamum indicum, Monodora myristica and Afzelia africana seeds from Nigeria. Pak. J. Nutr. 9, 368-372.

3. Omobuwajo, T.O., Omobuwajo, O.R. and Sanni, L.A. 2003. Physical properties of calabash nutmeg (Monodora myristica) seeds. J. Food Eng. 57, 375-381.

4. Ekeanyanwu, R.C. and Etienajirhevwe, O.F. 2012. In vitro antihelmintic potentials of Xylopia aethiopica and Monodora myristica from Nigeria. Afr. J. Biochem. Res. 6, 115-120.

5. Enabulele, S.A., Oboh, F.O.J. and Uwadiae, E.O. 2014. Antimicrobial, nutritional and phytochemical properties of Monodora myristica seeds. IOSR J. Pharm. Biol. Sci. 9, 1-6.

6. Onyenibe, N.S., Fowokemi, K.T. and Emmanuel, O.B. 2015. African nutmeg (Monodora myristica) lowers cholesterol and modulates lipid peroxidation in experimentally induced hypercholesterolemic male Wistar rats. Int. J. Biomed. Sci. 11, 86-92.

7. Akpojotor, P. and Kagbo, H.D. 2016. Histomorphological and biochemical effects of ethanolic extract of Monodora myristica seed (African nutmeg) on some liver function parameters using albino wistar rats. Brit. J. Med. Med. Res. 18, 1-9.

8. Ekeanyanwu, C.R., Ogu, I.G. and Nwachukwu, U.P. 2010. Biochemical characteristics of the African nutmeg-Monodora myristica . Agric. J. 5, 303-308.
9. Feyisayo, A. and Oluokun, O.O. 2014. Comparative analysis of phenolic profile of Monodora myristica and Monodora tenuifolia . Afr. J. Agric. Res. 9, 1296-1302.

10. Adewole, E., Ajiboye, B.O., Idris, O.O., Ojo, O.A. and Onikan, A., Ogunmodede, O.T. and Adewumi, D.F. 2013. Phytochemical, antimicrobial and GC-MS of African nutmeg (Monodora myristica). Int. J. Pharm. Sci. Invention. 2, 25-32.

11. Koudou, J., Etou Ossibi,A.W., Aklikokou, K., Abena, A.A., Gbeassor, M. and Bessiere, J.M. 2007. Chemical composition and hypotensive effects of essential oil of Monodora myristica Gaertn. J. Biol. Sci. 7, 937-942.

12. Oguntimein, B.O., Ekundayo, I.L. and Hitunen, R. 1999. Constituents of the essential oil of Monodora tenuifolia. Flav. Frag. J. 4, 193-195.

13. Akinwunmi, K.F. and Oyedapo, O.O. 2015. In vitro antiinflammatory evaluation of African nutmeg (Monodora myristica ) seeds. Eur. J. Med. Plants. 8, 167-174.

14. Bouba, A.A., Njintang, N.Y., Foyet, H.S., Scher, J., Montet, D. and Mbofung, C.M.F. 2012. Proximate composition, mineral and vitamin content of some wild plants used as spices in Cameroon. Food Nutr. Sci. 3, 423-432.

15. Sofowora, A.1993. Medicinal plants and traditional medicine in Africa. Spectrum Books, Ibadan, p.150.

16. Okwu, D.E. 2004. The phytochemicals and vitamins contents of indigenous spices of South Eastern, Nigeria. J. Sust. Agric. Environ. 6, 30-34

17. Crowell, P.L. 1999. Prevention and therapy of cancer by dietary monoterpenes. J. Nutri. 129, 775-778.

18. Tsuda, H., Ohshima, Y., Nomoto, H., Fujita, K., Matsuda, E., Iigo, M., Takasuka, N., Moore, M.A. 2004. Cancer prevention by natural compounds: in Drug Metabolism and Pharmacokinetics. The Japanese Society for the study of xenobiotics, Japan, 19, 245-263.

19. Flamini, G., Cioni, P.L., Morelli, I. 2005. Composition of the essential oils and in vivo emission of volatiles of four Lamium species from Italy: L. purpureum, L. hybridum, $L$. bifidum and L. amplexicaule. Food Chem. 91, 63-68.

20. Agiriga, A. and Siwela, M. 2017. Monodora myristica (Gaertn.) Dunal: A plant with multiple food, health and medicinal applications: A review. Am. J. Food Technol. 12, 271-284. 